\title{
QS能
}

Vanesa Álvarez*

José Manuel Freijo**

\section{LA PERSPECTIVA DE MAHARASTRA, LA EXPORTACIÓN ESPAÑOLA EN EL SECTOR DE BIENES INDUSTRIALES}

El estado indio de Maharastra y su capital, Mumbai, han liderado el desarrollo industrial de India en el último siglo. En la actualidad, las políticas del estado siguen buscando promover las fortalezas industriales de la región, entre las que destacan sus consolidadas instituciones, sus ventajas logísticas y la existencia de una amplia red de clústeres y servicios de apoyo en diferentes sectores.

Son muchos los retos y oportunidades que ofrece el mercado indio a las empresas españolas. A pesar de su complejidad, un enfoque de medio y largo plazo y un correcto entendimiento, planificación y seguimiento de este mercado permitirán explotar las ventajas comerciales que aún permanecen latentes en muchos sectores. Entre estos sectores de oportunidad, en el apartado industrial, destacan el de la automoción ligada a las nuevas formas de movilidad, el de la máquina herramienta y el de la maquinaria de envase y embalaje.

Palabras clave: Maharastra, Mumbai, desarrollo industrial, logística, automoción, máquina herramienta, envase, embalaje.

Clasificación JEL: D24, F14, L23, L52, R11.

\section{Introducción}

Con una población estimada de más de 123 millones de personas en la actualidad ${ }^{1}$, casi el triple que la de España, y una superficie de $307.690 \mathrm{~km}^{2}$, menos de dos tercios de la superficie de nuestro país, Maharastra es el segundo mayor estado de India en población y el tercero

\footnotetext{
* Consejera Económica y Comercial en Mumbai.

** Diplomado Comercial del Estado.

Versión de septiembre de 2020.

DOI: https:/doi.org/10.32796/bice.2020.3128.7094

1 El último censo es de 2011, cuando se contabilizaron unos $112 \mathrm{mi}-$ llones de habitantes.
}

en tamaño. Este territorio, situado en el oeste de India, cuenta con una gran línea de costa, de 720 kilómetros de longitud, a lo largo del mar Arábigo.

Maharastra es el estado más industrializado de India. Con un producto interior bruto (PIB) de 448.000 millones de dólares y un peso del $15,01 \%$ del PIB total, es la mayor economía del país. La ciudad de Mumbai, capital del estado, es sede de la mayoría de las corporaciones e instituciones financieras indias. Las principales bolsas de valores de India (BSE y NSE) y los principales mercados de materias primas están situados en esta ciudad. Mumbai cuenta con $\triangleright$ 
una de las áreas metropolitanas más grandes del mundo y es la mayor ciudad de India 2 .

Maharastra presenta una elevada tasa de urbanización, del 45,2\% según el censo de 2011 , mientras que la media de India no llega al $30 \%$, y es el estado más rico del país según varios estándares.

\section{Breve historia económica de Maharastra y de su capital, Mumbai}

Bombay se integró en la corona portuguesa en 1534, cuando todavía era una pequeña población asentada sobre un conjunto de islas próximas a la costa oeste de India. En 1661 Bombay pasó a control británico a raíz de un matrimonio entre miembros de las dos monarquías. La ciudad portuaria fue cedida a la Compañía de las Indias Orientales, la empresa británica que monopolizaba su comercio con India, el este y el sudeste de Asia, en 1668, pero su prosperidad no comenzó hasta el siglo XIX, coincidiendo con el debilitamiento de los regímenes gobernantes al norte y el este, con la recepción de inmigrantes comerciantes y artesanos, y con el refuerzo de las rutas comerciales tanto hacia dentro del territorio indio como hacia Europa.

Las primeras fábricas textiles se establecieron en Bombay a mediados del siglo xIx, y en 1860 ya era el primer mercado de algodón de India. La crisis del algodón en Estados Unidos por la guerra civil y la apertura del canal de Suez impulsaron la economía de Bombay. La urbe prosperó y fue escenario del desarrollo

\footnotetext{
2 Según el censo de 2011, Mumbai contaba con 18,41 millones de habitantes. Sin embargo, el fuerte crecimiento de la ciudad en las últimas décadas y la proliferación de barrios de chabolas o slums, algunos de los cuales superan el millón de residentes, han dejado esta cifra obsoleta.
}

del movimiento a favor de la independencia de India, finalmente declarada en 1947. Hasta 1960, Bombay fue la capital del estado de Bombay, que en esa fecha se disolvió para dar nacimiento a los actuales estados de Gujarat, al norte, y Maharastra, al sur, cuya capital sigue siendo la ciudad de Bombay.

En 1962 se creó la Corporación para el Desarrollo Industrial de Maharastra (MIDC), con el objetivo de establecer áreas industriales donde llevar a cabo una planificación y desarrollo industrial sistemático. A día de hoy MIDC sigue siendo la principal agencia de desarrollo de la infraestructura industrial de este estado indio.

Tras la Gran Huelga Textil de Bombay de 1982, la mayoría de las fábricas del centro cerraron y el sector textil entró en reconversión. Pero para entonces Bombay había diversificado su economía hasta convertirse en un importante centro financiero, comercial y de servicios, acogiendo también nuevas industrias como la metalúrgica, la química, la automoción o la electrónica.

Mumbai es la forma maratí (idioma local) de Bombay. El cambio de nombre de la ciudad se hizo oficial en 1995, cuando llegó al poder el partido nacionalista regional Shiv Sena, o Ejército de Shiva.

\section{Fortaleza empresarial}

En la actualidad los principales motores de la economía de Maharastra son las manufacturas, las finanzas ${ }^{3}$, el comercio internacional, los medios de comunicación de masas, la tecnología, el petróleo, la moda y el sector $\triangleright$

3 Tanto el Banco de la Reserva de India (RBI), que es el banco central del Estado, como la principal compañía de seguros del país, que es pública, tienen su sede en Mumbai. 
textil, las gemas y la joyería, las tecnologías de la información y la comunicación (TIC) y el turismo.

Maharastra se considera el primer estado y el líder del desarrollo económico e industrial de India. La calidad de sus infraestructuras, las políticas industriales arraigadas y diversas iniciativas para facilitar el clima de negocios han convertido a este estado en la sede de varias de las marcas indias más globales. Además de ser uno de los hubs del automóvil de India, centrado sobre todo en la ciudad de Pune y su área circundante, también destaca por la fortaleza en el sector de la producción y transformación de alimentos. Maharastra es líder en atracción de inversión extranjera directa (IED) en India. Según el Departamento de Promoción de la Industria y Comercio Interior (DPIIT), dependiente del Ministerio de Comercio e Industria de India, los flujos acumulados de IDE en Maharastra entre abril de 2000 y diciembre de 2017 ascendieron a 113.830 millones de dólares, un tercio de las entradas totales de IDE en el conjunto del país.

Maharastra también es el estado que más exporta de India, con unas exportaciones valoradas en 4,49 lakh ${ }^{4}$ crore $^{5}$ de rupias indias (casi 60.000 millones de dólares) en el año financiero 2017-2018. Entre sus exportaciones destacan las gemas y la joyería, la maquinaria y bienes de equipo, los productos farmacéuticos, los servicios del sector TIC, hierro y acero, vehículos y sus partes, algodón y productos agrícolas. Entre los sectores cuyas exportaciones el Gobierno maratí pretende potenciar en los próximos años figuran la confección textil, los bienes con alto componente de ingeniería,

4 El lakh es una unidad de medida india que equivale a cien mil (100.000).

5 El crore es una unidad de medida india que equivale a diez millones (10.000.000). las manufacturas agrícolas, las TIC y sus servicios, la automoción y sus componentes, y los sectores farmacéutico y químico.

El fuerte crecimiento económico de la región en los últimos años y su potencial a medio y largo plazo son indiscutibles. No obstante, en esta parte de India el desarrollo más moderno convive con importantes niveles de desigualdad y pobreza y con una frágil situación medioambiental. En los últimos meses, la prolongada crisis provocada por la pandemia de la COVID-19 ha ralentizado las perspectivas de crecimiento a corto plazo, tanto de Maharastra como del conjunto del país.

En el contexto del fuerte crecimiento que ha experimentado la economía india en los últimos años, han aparecido nuevos focos industriales, logísticos y de negocios en el país, que han crecido con fuerza y han logrado convertirse en líderes en sectores muy destacados, constituyéndose hoy en día en referencias globales y competidoras de Maharastra como capital industrial. Gujarat y su capital, Gandhinagar-Ahmedabad, en el noroeste, o Karnataka, con su capital, Bangalore, al sur, son ejemplos de los nuevos polos empresariales que han emergido en India.

Los esfuerzos del Gobierno de Maharastra siguen buscando mantener el rol de líder industrial y logístico de este estado en India: por un lado, se busca su consolidación como centro manufacturero proveedor del mercado interior y también volcado en la exportación; por otro, se pretende afianzar su papel como eje empresarial que conecta el norte y el sur de India.

Las autoridades maratíes se han fijado el ambicioso objetivo de llegar a ser una economía de un billón de dólares en 2025. Para ello se han propuesto fortalecer el ecosistema manufacturero de la región y lanzar nuevas $\triangleright$ 
facilidades para hacer negocios, entre las que destacan desarrollar infraestructuras a medida de las necesidades de la industria o crear un banco de terrenos a disposición de las empresas y adaptado a la demanda, a través del MIDC. Entre los objetivos más concretos figuran lograr que el crecimiento del sector manufacturero ronde el $12-13 \%$, de modo que su peso en el PIB estatal llegue hasta el $25 \%$ en 2023-2024; atraer inversiones por valor de 130.000 millones de dólares hasta 2023-2024, y crear oportunidades de empleo para cuatro millones de personas en 2023-2024.

\section{Fortaleza logística}

Maharastra está conectado a los principales centros industriales y de consumo del país. Según fuentes oficiales, 22.000 kilómetros de carreteras nacionales atraviesan el estado. Entre los nuevos proyectos en construcción destacan la autovía Maharashtra Samruddhi Mahamarg, un corredor de $700 \mathrm{Km}$ para conectar Nagpur y Mumbai, o la autovía entre Mumbai y Vadodara, en Gujarat. Aunque la red es voluminosa, debe tenerse en cuenta, no obstante, que, debido al tráfico, las condiciones de mantenimiento, las diferencias en calidad y la práctica de que los conductores ahorren combustible por todos los medios posibles, la velocidad media a la que se circula por las carreteras de Maharastra no supera los 60 o $70 \mathrm{Km} / \mathrm{h}^{6}$.

La conexión por ferrocarril con el mercado doméstico indio está asegurada a través de los corredores del norte y del noreste. En relación

\footnotetext{
6 Por ejemplo, entre Nueva Delhi y Mumbai hay unos 1.400 kilómetros de distancia por carretera. Por la vía más rápida, la Rajdhani Express, y sin tráfico, un vehículo de carga tardará unas dieciséis horas en recorrerla a una media de $87 \mathrm{Km} / \mathrm{h}$. Sin embargo, por carreteras normales, el trayecto puede requerir de cuarenta a sesenta horas, a una velocidad de entre 35 y $23 \mathrm{Km} / \mathrm{h}$.
}

al transporte urbano, en la actualidad están en construcción diversas líneas de metro en Mumbai, Nagpur y Pune. Maharastra cuenta con cuatro aeropuertos internacionales y once aeropuertos nacionales operativos.

Pero la verdadera fortaleza económica de Maharastra ha estado siempre ligada a su importante capacidad portuaria: este estado indio cuenta con dos puertos principales y hasta 53 puertos menores. Los dos principales puertos de Maharastra son Mumbai Port y Jawaharlal Nehru Port (JNP), siendo este último el mayor puerto de contenedores de India, antes conocido como Nhava Sheva. Ambos puertos principales están situados en los alrededores de la ciudad de Mumbai.

Entre los estados limítrofes de Maharastra destacan, por su dinamismo, Goa (un pequeño estado, importante destino turístico, y la región con mayor PIB per cápita de India), Gujarat y Karnataka (dos de los estados más dinámicos: el primero, un gran centro de producción agrícola y petrolera, sede de algunas de las grandes empresas del país; y el segundo, la referencia para el sector de las TIC, la ingeniería o la biotecnología, especialmente por su capital, Bangalore), y Telangana y Andhra Pradesh (dos estados que comparten capital, Hyderabad, líder en la producción farmacéutica y que destaca cada vez más por su potencial en TIC).

\section{Fortaleza industrial}

Según el informe Doing Business del Banco Mundial de 2020, India se situó en el puesto número 63 del mundo en términos de facilidad para los negocios. Esta posición supone una mejora de 14 puestos respecto a 2019 y de 37 puestos respecto a 2018. La ciudad de Mumbai ha sido la que más ha contribuido a este $\triangleright$ 
incremento en la facilidad para hacer negocios en India en los últimos años.

Desde sus inicios en los años sesenta, MIDC ha construido 289 áreas industriales en el estado, en más de 66.000 hectáreas de tierra, y ha desarrollado parques especiales para sectores como las TIC, la producción vinícola, o las gemas y la joyería, y entre los que destacan las zonas económicas especiales (SEZ, por sus siglas en inglés). Hoy en día MIDC cuenta con dieciséis oficinas regionales y sigue poseyendo una de las mayores reservas de tierra para uso industrial de India.

Maharastra cuenta con 32 zonas económicas especiales operativas, enclaves cuya infraestructura y gestión se agrupan bajo un mismo paraguas administrativo, que están pensadas para la localización de industrias que producen y exportan distintos tipos de bienes y servicios, y a las que se otorga un tratamiento fiscal preferente. A efectos del comercio con el resto del territorio indio, o de la provisión de servicios, las SEZ se consideran territorio extranjero. La creación de las zonas económicas especiales se remonta a la revisión de la política de importación-exportación del Gobierno indio del año 2000. Esta política ha atraído a numerosas empresas exportadoras a las SEZ de Maharastra, entre las que destacan Atos-Syntel, Infosys, Wipro o Mindspace.

La disponibilidad de una abundante fuerza de trabajo, con un amplio abanico de cualificaciones y habilidades, es otra de las fortalezas de este enclave industrial. Maharastra cuenta con veinte universidades estatales, veintiuna universidades adscritas, e importantes institutos, entre los que destacan el Instituto Indio de Tecnología de Bombay (IIT), el más antiguo de India, el Instituto Nacional de Tecnología de la Moda de Mumbai (NIFT), el Instituto Tata de Ciencias Sociales (TISS), el Instituto
Nacional de Gestión e Investigación de la Construcción (NICMAR), el Instituto de Tecnología Química de Mumbai (ICT), etc.

La capacidad de generación eléctrica de Maharastra supera los $43.000 \mathrm{MW}$, lo que permite asegurar el suministro eléctrico a sus empresas y habitantes. Esta cuestión no es insignificante, pues en algunas partes de India todavía son frecuentes los cortes de electricidad en los meses de mayor calor y en la temporada de monzón, entre junio y septiembre.

Los principales clústeres industriales de Maharastra se localizan en las siguientes regiones:

- Automóvil: área en torno a Pune y Aurangabad.

- ESDM (diseño y fabricación de sistemas electrónicos): área en torno a Pune.

- Farmacéutica y química: Mumbai-Thane, Pune y Aurangabad.

- Ingeniería: Ahmednagar-Nashik, Pune y Aurangabad.

- FMCG (bienes de consumo de rotación rápida): Pune.

- Textil: Solapur y Nagpur-Amravati.

- Procesado de alimentos: Solapur, Ahmednagar-Nashik, y Nagpur-Amravati.

- Cemento y acero: Vidarbha-Marathwada.

- TIC y servicios de TIC: Mumbai-Thane, Pune y Nagpur-Amravati.

Entre otras iniciativas incluidas en la política industrial de Maharastra 2019, el Gobierno estatal ha creado el Fondo de Infraestructuras Industriales Críticas (CIIF), dotado con 1.000 crores de rupias indias (unos 130 millones de dólares) para desarrollar infraestructuras en áreas industriales no cubiertas por la MIDC, especialmente en las áreas de conectividad $\triangleright$ 
por carretera de última milla, y de refuerzo del suministro de agua y de electricidad. Otra de las iniciativas consiste en crear nuevas instituciones, como el Consejo de Promoción de la Inversión Global (GIPC) de Maharastra, dedicado a atraer a inversores globales al estado, facilitando el desarrollo de la marca Magnetic Maharashtra, o el Consejo de Promoción de la Exportación de Maharastra, a imagen de los consejos sectoriales que ya existen a nivel central.

A nivel sectorial, siguen vigentes las políticas sectoriales específicas diseñadas en los últimos años, entre las que destacamos la Política de Vehículo Eléctrico e Infraestructura Relacionada de 2018, la Política del Textil de 2018 o la Política de la Electrónica de 2016.

Entre los proyectos del Gobierno central de India que seguirán impulsando a Maharastra como líder industrial de India destaca el Corredor Industrial Delhi Mumbai (DMIC), un gran programa de infraestructuras dirigido a desarrollar nuevas ciudades industriales inteligentes, del que cuelgan dos proyectos en Maharastra: Shendra Bidkin Industrial Area (SBIA), una superficie de en torno a $84 \mathrm{~km}^{2}$ próxima a Aurangabad, y Dighi Port Industrial Area (DPIA), una zona industrial de $253 \mathrm{~km}^{2}$ en torno a Mumbai.

\section{La exportación española en el sector de bienes industriales}

Las primeras empresas españolas que se instalaron en Maharastra llegaron hace más de dos décadas atraídas tanto por las ventajas productivas de este importante centro de producción industrial como por el extenso mercado indio que se abre a sus puertas. A pesar de la crisis de 2008 y de las vicisitudes y el tiempo que requiere una implantación definitiva $y$ sólida en India, el número de empresas industriales españolas en India ha seguido creciendo de manera lenta pero sostenida, de modo que nuevas empresas han ido apostando por la región, y son varias las existentes que han ampliado su capacidad productiva.

La elección de la localización de las empresas en India obedece a factores muy diversos, que van desde la existencia de un clúster o un centro de aprovisionamiento de materias primas, logístico o de capital humano especialmente adecuado para las necesidades de la empresa, hasta la proximidad a los clientes (a menudo, otras empresas extranjeras implantadas también en India con las que existe una relación comercial a nivel global) o la existencia de incentivos fiscales o administrativos. En el estado de Maharastra, los destinos preferidos de las empresas industriales españolas han sido Pune (automoción, máquina herramienta, ingeniería, envase y embalaje) y Mumbai (servicios de construcción y conexos, productos siderúrgicos, medio ambiente y producción energética).

A pesar de lo anterior, hoy en día, la presencia de empresas industriales españolas implantadas en India sigue siendo modesta. La mayor parte del comercio del sector se sigue canalizando a través de la exportación. $Y$ esto es así porque, si bien hay numerosas ventajas en la implantación en el contexto de un mercado que es cada vez más proteccionista respecto al exterior, persisten dificultades administrativas, problemas de eficiencia y diferencias en la cultura empresarial, que en ocasiones afloran en la relación con los socios locales, que hacen que la implantación sea una decisión compleja que debe valorarse muy cuidadosamente.

La crisis provocada por la pandemia de la COVID-19, especialmente persistente en $\triangleright$ 
India, ha dado lugar a una revisión de las estrategias empresariales en todo el mundo. En Maharastra, las empresas señalan como importantes retos actuales la liquidez, la gestión de las cadenas de valor, y la reconversión estratégica necesaria para adaptarse a los componentes permanentes de los cambios en la demanda que ha provocado la crisis de la COVID-19.

A pesar de la crisis actual, tres sectores industriales siguen liderando las oportunidades en India: el de la automoción, el de la máquina herramienta y el de la maquinaria de envase y embalaje. En conjunto, el saldo comercial de España con India en estos sectores no refleja la fortaleza competitiva reconocida a nuestra industria a nivel global. Existe margen para el crecimiento del comercio y para un mejor aprovechamiento de las oportunidades que brinda el mercado indio en estos tres sectores:

- Componentes de automoción. India es la cuarta potencia mundial en el sector de la automoción, un sector que en los últimos años ha estado creciendo a tasas cercanas al $10 \%$ anual. A pesar del reto que supone la reconversión del sector en todo el mundo, y de la caída adicional de las ventas que ha provocado la crisis de la COVID-19, la movilidad avanzada y en concreto, la transición hacia vehículos eléctricos y nuevas formas de movilidad en todos los segmentos, plantean importantes oportunidades comerciales y de inversión. La mayoría de las empresas españolas del sector están implantadas en India. En el año fiscal 2018-2019, las exportaciones totales de este sector desde India ascendieron a $15.160 \mathrm{mi}-$ llones de dólares, mientras que las importaciones se situaron en 17.169 millones de dólares.

- Máquina herramienta. Las exportaciones españolas a India no reflejan ni el volumen ni la competitividad que posee la industria española de máquina herramienta a nivel global. Según la asociación india de máquina herramienta IMTMA (Indian Machine Tool Manufacturers Assosciaton), las importaciones totales del sector en India ascendieron a 1.906 millones de dólares en el año fiscal 2018-2019, destacando la importación procedente de España en las partidas arancelarias 8459 (máquinas para perforar) y 8462 (máquinas para trabajar metales). En general, existe un importante margen de crecimiento en este mercado para las empresas españolas, especialmente para atender a los sectores de automoción y componentes, equipos de defensa, maquinaria eléctrica y ferrocarril.

- Maquinaria de envase y embalaje. Antes de la crisis de la COVID-19 se estimaba que la industria del packaging en India seguiría creciendo a tasas superiores al $7 \%$ anual. La maquinaria española está bien valorada en India y las importaciones procedentes de España han aumentado considerablemente en los últimos cinco años. Destaca, en especial, el despunte para las importaciones de la partida arancelaria 8422 (máquinas para lavar vajilla, limpiar o secar recipientes para llenar, cerrar o tapar botes, latas, bolsas, etc.) y de la partida 8441 (máquinas para el trabajo de papel y cartón). No obstante, España todavía no cuenta con una cuota de mercado significativa en las importaciones del sector. 


\section{Conclusión}

El estado de Maharastra continúa liderando una buena parte de la producción industrial de India. Es un estado dinámico, con una economía fuerte y diversificada, volcado en potenciar la industria y en desarrollar políticas que le permitan mantener su rol como eje productivo, logístico y financiero de India.

Son muchos los retos y oportunidades que ofrece el mercado indio a las empresas españolas. A pesar de su complejidad, un enfoque de medio y largo plazo y un correcto entendimiento, planificación y seguimiento de este mercado permitirán explotar las ventajas comerciales que aún permanecen latentes en muchos sectores. Entre estos sectores de oportunidad, en el apartado industrial, destacan el de la automoción ligada a las nuevas formas de movilidad, el de la máquina herramienta y el de la maquinaria de envase y embalaje.

La crisis de la COVID-19 está golpeando con una dureza sin precedentes a la economía india. No obstante, a medio y largo plazo las perspectivas de crecimiento de los sectores industriales indios siguen siendo muy positivas. En este momento es importante ir conociendo este mercado y estableciendo vínculos sólidos con clientes y socios con el fin de posicionarse adecuadamente de cara a la futura recuperación.

\section{Bibliografía}

Oficina Económica y Comercial de España en Mumbai (2018). Estudio de mercado. El mercado de la máquina herramienta en India 2018. ICEX España Exportación e Inversiones. https://www. icex.es/icex/es/navegacion-principal/todosnuestros-servicios/informacion-de-mercados/ paises/navegacion-principal/el-mercado/estudios-informes/DOC2019811106.html?idPais=IN

Oficina Económica y Comercial de España en Mumbai (2019). Estudio de mercado. El mercado de componentes de automoción en India 2019. ICEX España Exportación e Inversiones. https://www. icex.es/icex/es/navegacion-principal/todosnuestros-servicios/informacion-de-mercados/ paises/navegacion-principal/el-mercado/estudios-informes/DOC2019815494.html?idPais=IN

Oficina Económica y Comercial de España en Mumbai (2019). Estudio de mercado. El mercado de maquinaria de envasado y embalaje en India 2019. ICEX España Exportación e Inversiones. https://www.icex.es/icex/es/navegacion-principal/todos-nuestros-servicios/informacion-demercados/paises/navegacion-principal/el-mercado/estudios-informes/DOC2019827166.html ?idPais=IN

Oficina Económica y Comercial de España en Mumbai (2020). Ficha sector. Maquinaria de envasado y embalaje en India 2020. ICEX España Exportación e Inversiones. https://www.icex.es/ icex/es/navegacion-principal/todos-nuestrosservicios/informacion-de-mercados/paises/navegacion-principal/el-mercado/estudios-informes/DOC2020852250.html?idPais=IN

Oficina Económica y Comercial de España en Mumbai (2020). Ficha sector. Vehículos eléctricos en India 2020. ICEX España Exportación e Inversiones. https://www.icex.es/icex/es/navegacionprincipal/todos-nuestros-servicios/informacion-de-mercados/paises/navegacion-principal/ el-mercado/estudios-informes/DOC2020855 648.html?idPais=IN

Oficina Económica y Comercial de España en Mumbai (2020). Nuevas Estrategias Empresariales frente a la COVID-19 en India. ICEX España EXportación e Inversiones. https://www.icex.es/icex/ es/navegacion-principal/todos-nuestros-servicios/informacion-de-mercados/paises/navegacion-principal/el-mercado/estudios-informes/ DOC2020856213.html?idPais=IN

Oficina Económica y Comercial de España en Mumbai (2020). Principales medidas $D$ 
empresariales ante la COVID-19 en India 2020. ICEX España Exportación e Inversiones. https:// www.icex.es/icex/es/navegacion-principal/ todos-nuestros-servicios/informacion-demercados/estudios-de-mercados-y-otros-documentos-de-comercio-exterior/DOC2020 852824.html

\section{Páginas web consultadas}

Doing Business in Maharashtra. http://www.doingbusinessinmaharashtra.org/
Enciclopedia Británica. https://www.britannica.com/ place/Mumbai/History

India Brand Equity Foundation. https://www.ibef.org/ states.aspx

Maharashtra Industrial Development Corporation. https://www.midcindia.org/home https://www.midcindia.org/documents/20181/26611/About+ MIDC.pdf/9015b57f-379e-4534-8265-53bb8 bbd846c

Maharashtra Industry, Trade and Investment Facilitation Cell. https://maitri.mahaonline.gov.in/ 
